\section{Thermal Expansion of Coal}

The physical properties of coal have not yet been adequately studied. Consequently, proposed models of coal structure cannot be tested nor apparently conflicting experimental observations reconciled. We advocate that accurate measurement of such properties of coal as the thermal expansion, electrical conductivity, and response to mechanical stress should be made concurrently with chemical and physical researches which seek to elucidate the structure of the material in increasingly specific terms.

Accordingly, we have made preliminary measurements of the coefficient of thermal expansion of a limited range of British bright coals in a direction parallel to the bedding plane and normal to the main cleat over the temperature range $77^{\circ}-293^{\circ} \mathrm{K}$.

Changes in the length of small coal lumps have been measured by a capacitance method which has been chosen as sufficiently accurate and convenient in the first instance. The condenser assembly consists of a fused quartz plate upon which rests a short cylinder of the same material bearing the upper condenser plate, a circular copper disk $30 \mathrm{~mm}$. in diameter with three lugs. Resting upon the quartz plate and within the cylinder is a disk of copper upon which stand three like coal specimens supporting the lower condenser plate. The whole assembly is contained within a vessel which can be evacuated and chilled. The coal specimens are cut from bright clarain in the form of tetrahedra $10 \mathrm{~mm}$. high the bases of which are parallel to the main cleat. We have not yet measured the coefficient of thermal expansion parallel to the main cleat or normal to the bedding plane. The capacity ehange resulting from a change in the temperature of the coal specimens has in these experiments been measured by a commercial instrument in which the incremental capacity can be caused to occupy the whole of the measuring scale.

The measurements relate to dry coal, the specimens having been exposed over magnesium perchlorate for thirty-six hours before use and the vessel containing the complete electrode assembly maintained at $10^{-1} \mathrm{~mm}$. mercury for the twelve hours before the introduction of nitrogen ( $15 \mathrm{~mm}$. mercury) in readiness for initial measurement and chilling. The observations made have included the change in linear dimension on chilling from room temperature to $77^{\circ} \mathrm{K}$. and, using a series of refrigerants, during warming from that temperature to room temperature.

Our results for four British bright coals, including a sample of anthracite (sample $D$ ), are in Table 1 . These supplement the few published values of which we are aware, namely, $20^{-78} \times 10^{-6}$ for anthracite ${ }^{1}$ and $42 \times 10^{-8}$ for a low-rank bituminous coal ${ }^{2}$ (carbon content $82 \cdot 6$ per cent dry mineral-free basis).

Table 1. Confficient of Expansion in the Bedding Plane of

\begin{tabular}{|c|c|c|c|c|c|}
\hline Coal & $A$ & $B$ & $C$ & \multicolumn{2}{|c|}{$D$} \\
\hline $\begin{array}{l}\text { Carbon, per cent dry, } \\
\text { mineral-free basis }\end{array}$ & 82 & 87 & $90 \cdot 5$ & \multicolumn{2}{|c|}{$94 \cdot 5$} \\
\hline $\begin{array}{c}\text { Temperature range }\left({ }^{\circ} \mathrm{K} .\right) \text { : } \\
293-77 \\
77-90 \\
90-217 \\
217-273 \\
273-293\end{array}$ & $\begin{array}{l}40 \\
35 \\
43 \\
42 \\
35\end{array}$ & $\begin{array}{l}51 \\
32 \\
40 \\
49\end{array}$ & $\begin{array}{l}36 \\
42 \\
47 \\
31 \\
59\end{array}$ & $\begin{array}{l}51 \\
54 \\
23 \\
49 \\
31\end{array}$ & $\begin{array}{r}22 \\
12 \\
8 \\
36 \\
\end{array}$ \\
\hline
\end{tabular}

The mean values for the full temperature range are probably accurate to $\pm 2 \times 10^{-8}$. The error in the values ascribed to intermediate temperature ranges may be somewhat larger. We are aware of imperfections in both the method and the apparatus. These we hope to reduce. Nevertheless, the values stated are sufficiently accurate to be useful.

The similarity between the observed values for the three bituminous coals ( $A, B$ and $C$ ) suggests that the differences in the arrangement of solid and space which are consequent upon the change in rank from low-rank non-caking to coking coal have been almost offset by changes in the properties of the solid. The wide range in the values obtained with two sets of anthracite specimens $(D)$ reflects the anisotropy of the material.

We do not doubt that if such data had been available a few years ago the inappropriate over-simplification of such a model for coal as that of Bangham ${ }^{3}$ would quickly have been apparent.

We hope to continue our measurements with increasing accuracy and completeness.

$$
\text { J. C. Macrat }
$$

C. RYDER*

Department of Coal Gas and

Fuel Industries with Metallurgy, University, Loeds 2. March 25.

* Present address: South Eastern Gas Board, Katharine Street, Croydon, Surrey.

1 Smithsonian Tables.

Bond, R. L., Griffith, M., and Moggs, F. A. P., Fuel, 29, 88 (1950).

'Bangham, D. H., Franklin, R. E., Hirst, W., and Moggs, F. A. P., "Coal Research", 153 (1948).

\section{F-Centres in Metaphosphate Glass}

A NUMBer of investigators ${ }^{1}$ have shown that glass on exposure to radioactive and $\mathrm{X}$-radiation becomes coloured. Sheline, Sharp and Arner ${ }^{2}$ suggested that this may be due to $F$-centres similar to those produced in alkali halides when bombarded by X-rays and cathode rays. Yokota ${ }^{3}$ found that $F$-centres could be created in fused silica and $\alpha$-quartz by $\mathrm{X}$-irradiation. He further showed that alkali silicate and borate glasses become coloured on X-irradiation due to formation of $F$-centres ${ }^{4}$. Przibram ${ }^{5}$ showed that $F$-centres could also be created in borate glass by $\beta$ - and $\gamma$-irradiation from radium.

I have found that $F$-centres can be produced very easily in metaphosphate glass by $\mathrm{X}$-irradiation from a copper target $(30 \mathrm{kV}$., $15 \mathrm{~m}$.amp.). These metaphosphate glasses were prepared by heating sodium dihydrogen phosphate in a platinum tray at $900^{\circ} \mathrm{C}$. for $1 \mathrm{hr}$. Variation in the composition of the glass could be introduced by heating mixtures of sodium dihydrogen phosphate and disodium hydrogen phosphate, and mixtures of sodium dihydrogen phosphate and ammonium dihydrogen phosphate. In the first case, sodium was in excess of the stoichiometric composition, while in the second case phosphate radical was in excess, ammonia disappearing during heating. Composition, however, could not be varied over a wide range, for metaphosphate glass with higher sodium content tended to crystallize out rather quickly.

Absorption spectra measurements were carried out with glass plates $(0.8 \mathrm{~mm}$. thick) in a Beckman spectrophotometer model $D U$. The irradiated glass system showed two peaks in the visible region at $510 \mathrm{~m} \mu$ and $490 \mathrm{~m} \mu$ respectively, and one in the 